\title{
4
}

\section{Artificial Acellular Feeder Layer: An Advanced Engineered Extracellular Matrix for Stem Cell Culture}

\author{
Amranul Haque ${ }^{1}$, Masato Nagaoka ${ }^{1,2}$, Xiao-Shan Yue , \\ Stephen A. Duncan ${ }^{2}$ and Toshihiro Akaike ${ }^{1}$ \\ ${ }^{1}$ Tokyo Institute of Technology, Yokohama \\ ${ }^{2}$ Medical College of Wisconsin, Milwaukee, Wisconsin \\ 1.bpan \\ ${ }^{2} U S A$
}

\section{Introduction}

Stem cell behavior and function is influenced by a complicated 3-D microenvironment consisting of extracellular matrix (ECM), neighboring cells, growth factors, hormones, and nutrients (Discher et al., 2009). Among them cell-ECM interaction regulates many aspects of cell behavior, including cell survival, growth, proliferation, differentiation, migration, and morphogenesis (Fig. 1) (Hynes, 1992). Tissue engineering strives to replace damaged tissues with stem cells seeded onto biologically derived or synthetic materials to mimic the regulatory characteristics of ECM and thus restore the normal control of cell function. In general, materials from natural sources (e.g., collagen, laminin or fibronectin) are advantageous for cell culture because of the presence of cell recognizable receptors (e.g., ECM molecule, galactose, can specifically recognize asialoglycoprotein receptor (ASGPR) on the hepatocytes) (Cho et al., 2006; Lutolf \& Hubbell 2005). However, critical problems in biocompatibility, mechanical properties, degradation, pathogen transmission and numerous other areas remain. For tissue-engineering strategies to be successful, the complicated relationship between cells and the ECM must be simplified in a way to understand appropriate cell behavior. Through the design and expression of artificial genes using recombinant DNA technology, it is now possible to prepare artificial ECM proteins with controlled mechanical properties and with domains chosen to modulate cellular behaviour (Nagaoka et al., 2002; Ogwara et al., 2005; Azuma et al., 2010; Yue et al., 2010). This approach avoids several important limitations encountered in the use of natural ECM proteins, including complex purification, immunogenicity, heterogeneous environment, batch-to-batch (or source-to-source) variation in materials isolated from tissues, and presence of xenogenetic compounds. Moreover, the designing of artificial extracellular matrix should enable more efficient and scalable culture of embryonic stem (ES) or induced pluripotent stem (iPS) cells, as well as greater control over material properties and tissue responses (Haque et al., 2010; Nagaoka et al., 2010a). 


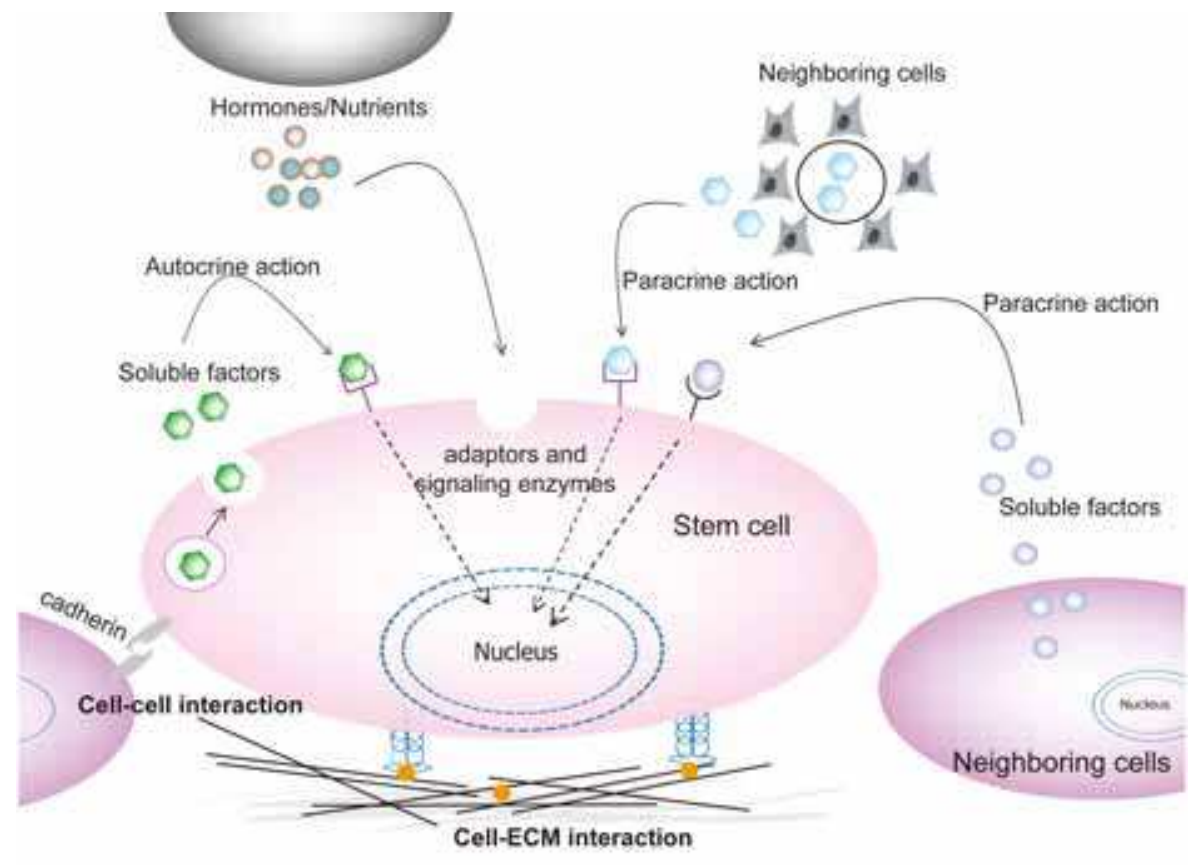

Fig. 1. Components of stem cell microenvironment that determine cell fate. Stem cell behavior that is proliferation, differentiation, migration and apoptosis is influenced by coordinated interaction of soluble factors, extracellular matrix and signals from neighboring cells. Specific binding of signal molecules with cell-surface receptors induces complex intracellular signaling pathways with subsequent effect on gene expression, self-renewal, morphogenesis and differentiation (Lutolf \& Hubbell 2005)

\section{Classification of extracellular matrix for ES cell}

The ECM is a complex composite of fibrous structural proteins (e.g. collagen, laminin, elastin, or fibronectin) and specialized proteins (e.g. growth factors, glycoproteins and proteoglycans. It provides an important model for biomaterial design (Langer \& Tirrell, 2004). ECM can be broadly categorized into natural and recombinant considering ES cell culture, self-renewal and differentiation.

\subsection{Natural extracellular matrix}

Various amounts and types of collagens, laminin, elastin, matrigel, fibronectin, vitronectin, or proteoglycans have been used as natural extracellular matrices (Nagaoka et al., 2010a). Generally, gelatin, that has a history of extensive use in myocardial and neural tissue engineering, can provoke an unspecific inflammatory response (Akhyari et al., 2008). Recently, it has been shown that natural matrix molecule (fibronectin-coated collagen gel) can induce the directed differentiation of endoderm from mouse embryonic stem (mES) cells without any requirement of cell sorting (Parashurama et al., 2008). But due to less control on structural composition of ECM, cell-matrix interaction and use of complex serum- 
supplementation, it was difficult to find the exact mechanism of collagen gel on directed differentiation of endoderm cells. Moreover, Eschenhagen et al. (1997) have established one of the convincing models of 3-D cardiac cell cultures using matrigel, where differentiation status and functional parameters reach a quality close to that of native myocardium. However, still there has been some controversy about matrigel and the question of the growth factor content within matrigel has been partially regarded as a potential contaminant. Furthermore, some of these components have no regulatory approval for use in human patients (Akhyari et al., 2008).

\begin{tabular}{|l|l|l|l|l|}
\hline Categories & Targets & $\begin{array}{l}\text { Fused } \\
\text { domain }\end{array}$ & Advantages & References \\
\hline $\begin{array}{l}\text { Cell-cell interacton } \\
\text { molecules }\end{array}$ & $\begin{array}{l}\text { E- or N- } \\
\text { cadherin }\end{array}$ & IgG Fc & $\begin{array}{l}\text { Increased cell adhesion, } \\
\text { growth and transfection, } \\
\text { efficient differantiation }\end{array}$ & $\begin{array}{l}\text { Nagaoka et } \\
\text { al., 2006; Yue } \\
\text { et al., 2010 }\end{array}$ \\
\hline Growth factor & LIF & IgG Fc & $\begin{array}{l}\text { Strong and stable } \\
\text { signaling, controlled } \\
\text { presentation }\end{array}$ & $\begin{array}{l}\text { Nagaoka et } \\
\text { al., 2008b }\end{array}$ \\
\hline Co-immobilized & $\begin{array}{l}\text { E-cadherin } \\
\text { and LIF }\end{array}$ & IgG Fc & $\begin{array}{l}\text { Less dependency on LIF, } \\
\text { single cell morphology, } \\
\text { controlled pluripotency }\end{array}$ & $\begin{array}{l}\text { Nagaoka et } \\
\text { al., 2008b }\end{array}$ \\
\hline
\end{tabular}

Table 1. Characteristics of recombinant fusion proteins for stem cell culture and differentiation (Nagaoka et al., 2010a)

\subsection{Recombinant extracellular matrix}

In recent years, artificial ECMs gained special interest due to their excellent mechanical properties, process ability and low cost (Gupta et al., 2002). It is expected that synthetic ECMs can mimic many functions of the natural ECM including cellular 3-D architecture, mechanical integrity to the new tissue and the space for the diffusion of nutrients and metabolites (Putnam and Mooney, 1996). Among synthetic ECM molecules, the use of functional fusion proteins shows great promise in biology and biomedical technology due to simple and cheap production and purification strategy. Mostly three categories of synthetic ECM using recombinant fusion proteins have been explored by Akaike group in stem cell culture research (Table 1) (Nagaoka et al., 2010a; Haque et al., 2010). First, fusion proteins targeting cell-cell interacton molecules, such as cadherins (Nagaoka et al., 2006; Yue et al., 2010). Nagaoka and coworkers has also been reported second categories of fusion proteins targeting cell-bound growth factor. A co-immobilized matrix consisting both types of fusion proteins can also used for stem cell culture and pluripotency (Nagaoka et al., 2008b).

\subsubsection{Cell-cell adhesion molecule based extracellular matrix}

Cadherins are most important family of Ca2+-dependent intercellular adhesion molecules that may play a role in selective cell adhesion (Miyatani et al., 1989). Akaike and coworkers used two members of this family, epithelial cadherin (E-cadherin) and neural cadherin (N-cadherin) as ECM molecule to culture and differentiate ES cells (Nagaoka et al., 2006; Yue et al., 2010). The different cadherin types exhibit distinct tissue distribution pattems (Takeichi et al., 1981). 


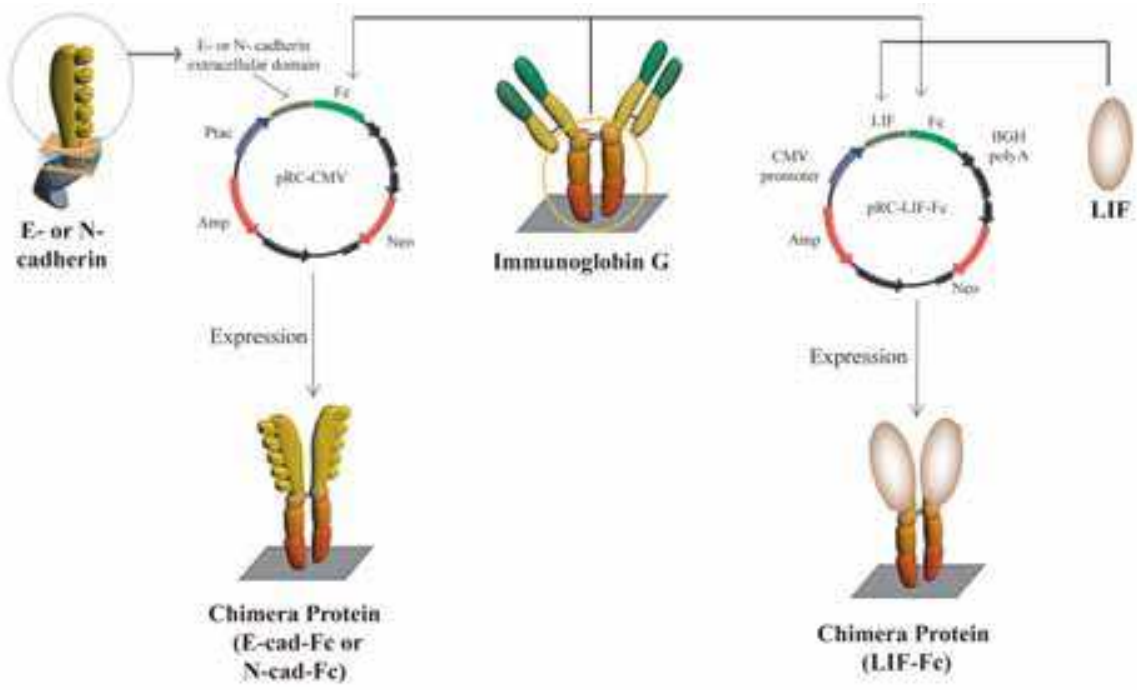

Fig. 2. Construction of fusion proteins for artificial extracellular matrix. Generated segments of an extracellular domain of mouse E-cadherin, N-cadherin or LIF and IgG Fc region were subcloned into a eukaryotic expression vector $\mathrm{pRC/CMV.} \mathrm{CMV} \mathrm{promoter,} \mathrm{human}$ cytomegalovirus immediate-early promoter/enhancer; BGH poly A, bovine growth hormone polyadenylation signal; Amp, ampicillin resistance gene; Neo, neomycin resistance gene (Nagaoka et al., 2002; 2006; 2008b; Yue et al., 2010)

It has been known that E-cadherin mediated cell-cell interaction is essential for tissue morphogenesis and is also required for maintenance of organized solid tissues (Ozawa et al., 1990). The C-terminal domain of E-cadherin is associated with cytoplasmic proteins (a-, $\beta-, \gamma$-catenin and $\mathrm{p} 120 \mathrm{ctn})$ and this molecular complex regulates homophilic interaction and dimerization of E-cadherin in presence of $\mathrm{Ca}^{2+}$ (Ozawa et al., 1990, Takeichi, 1995; Brieher et al., 1996). The temporal and spatial expression of E-cadherin on the surfaces of different types of cells is essential for different cellular regulatory functions. For example, E-cadherin plays a central role during preimplantation embryonic development. In its absence, proper cell polarization is absent and trophectoderm formation is impaired (Larue et al., 1994; Reithmacher et al., 1995). Moreover, E-cadherin may fine-tune ES cell pluripotency by modulating intracellular $\beta$-catenin levels or Nanog expression (Chuo et al., 2008). E-cadherin can also regulate differentiation of ES cells by modulating its expression or expression of transcription factors (Nishikawa et al., 2005). Nagaoka et al. showed that the use of artificial ECM in absence of these natural adhesion molecules can also support both undifferentiated and differentiated cells to function according to their native counterparts. Designing of artificial ECM with immobilized extracellular domain of E-cadherin as insoluble ligands not only facilitated efficient proliferation of mES cells with scattering behavior (Nagaoka et al., 2008a) but also showed enhance cell attachment and differentiation of primary hepatocytes (Nagaoka et al., 2006; 2008a). In chimeric protein of E-cadherin extracellular domain and IgG-Fc region (abbreviated as E-cad-Fc) (Fig. 2), the E-cadherin primarily attach to ECM through Fc region that has the potentiality to stably adsorb to a plastic surface such as polystyrene and dimerize via the hinge region. On the other hand, the extracellular domain of E-cadherin holds cells through homophilic interaction and thereby, activates specific 
signaling pathways. The creation of such type of highly defined artificial matrix molecules can improve mechanical performance and help in finding the complexity of signaling in cellECM interactions (Fig. 4) (Nagaoka et al., 2010a).

The scond type of cadherin molecule, $\mathrm{N}$-cadherin, is expressed in various neural tissues and has been implicated in the attachment of axons to other cells, raising the possibility that this molecule is involved in neuronal recognition mechanism (Miyatani et al., 1989). Especially in central neural system, $\mathrm{N}$-cadherin mediated the interaction between neurons and astrocytes. Also, the interaction between fibroblast growth factor receptor (FGFR) and the extracellular domain 4 of $\mathrm{N}$-cadherin promoted the extension of neurites, indicating the very close relationship between $\mathrm{N}$-cadherin and neural system formation and function (Williams et al., 2001). Yue and coworkers (2010) also constructed another fusion protein, Ncadherin fused to IgG-Fc (abbreviated as N-cad-Fc), by fusing the extracellular domain of Ncadherin and the Fc fragment of mouse IgG protein (Fig. 2). The development of this type of defined extracellular matrix favors the development of homogeneous culture conditions for ES cell differentiation under single cell level.

\subsubsection{ECMs with immobilized fusion protein of soluble factors}

Growth factors play an important role in regulating cellular behavior and function, such as proliferation, migration and differentiation. The biological signals of growth factors and cytokines are mediated by two different forms, the secreted form and the cell membrane- or matrix-anchored form, which release different signal transduction cascades (Tanaka et al., 1998). Controlled release of growth factors from engineered ECM can facilitate analysis of cellular morphogenesis, cell-cell interaction and monitoring of signaling pathways (Nagaoka et al., 2002). Ogiwara et al. (2005) proposed a novel artificial extracellular matrix with immobilized recombinant epidermal growth factor (EGF) fused to an IgG-Fc region (abbreviated as EGF-Fc) to investigate the effect of this matrix on phosphorylation of EGF receptor, the activation of mitogen-activated protein kinase (MAPK) and morphological changes in the cytoskeleton. Compared to soluble EGF, immobilized EGF-Fc showed more strong and stable activation of MAPK in A431 cells. Moreover, activation of Ral and cdc42 was found in A431 cells on immobilized EGF-Fc coated surface, but absent on collagen gels (Ogiwara et al., 2005). Besides, as growth factors are required in only very tiny quantities to elicit biological response, designing artificial matrices for controlled growth factor presentation is necessary. Recently, many studies showed the difficulties in using soluble leukemia inhibitory factor (LIF) to control self-renewal of mES cells without differentiation (Ying et al., 2003a). Considering these limitations together with analysis of cell behavior and function, Nagaoka and coworkers proposed matrix anchored form of LIF to design artificial acellular feeder layer for mES cells. The undifferentiated state of mES cells was maintained on the surface coated with chimeric protein, LIF-Fc (Fig. 2). Furthermore, when cultured on the co-immobilized surface with LIF-Fc and E-cad-Fc, mES cells showed undifferentiated state and pluripotency without additional LIF supplementation. This study showed that immobilized LIF and E-cadherin can maintain mES cells efficiently and that the immobilzable LIF-Fc fusion protein is useful for the investigation of signaling pathways of an immobilized form of LIF in the maintenance ES cell pluripotency (Nagaoka et al., 2008b).

\subsubsection{Extracellular matrix with co-immobilized fusion proteins}

The combination of cell-adhesive matrix and a controlled-signaling scheme for a growth factor could allow stem cells to control cultivation and self-renewal in an efficient way (Fig. 3). Moreover, the spatial and temporal expression of genes at different developmental stages 
further necessities the use of co-immobilized matrix to induce differentiation of embryonic stem cells towards specific lineages of populations. Nagaoka and co-workers applied two immobilizable model proteins, E-cad-Fc and LIF-Fc, to establish a new culture system of mouse ES cells, and demonstrated that mouse ES cells can be effectively maintained on a coimmobilized surface with the model proteins (Nagaoka et al 2008b).

\section{Culture of ES cells on recombinant extracellular matrix}

The purpose of using extracellular matrices to culture ES cells is many folds: (i) proliferation of cells under fully defined and homogeneous culture conditions, (ii) to mimic the process of cell differentiation, and (iii) to generate a specific type of mature cells at a high purity (Nagaoka et al., 2006; 2008b; Nishikawa et al., 2007). Although some progress has been made, this is still difficult to achieve homogeneous and fully defined culture environment. Despite this intractable problem, continuous attempts have been made to proliferate and differentiate ES-cell under homogeneous conditions in the absence of EB formation. For proliferation of ES cells in monolayer cultures with homogeneous environment, only few successes have been reported.

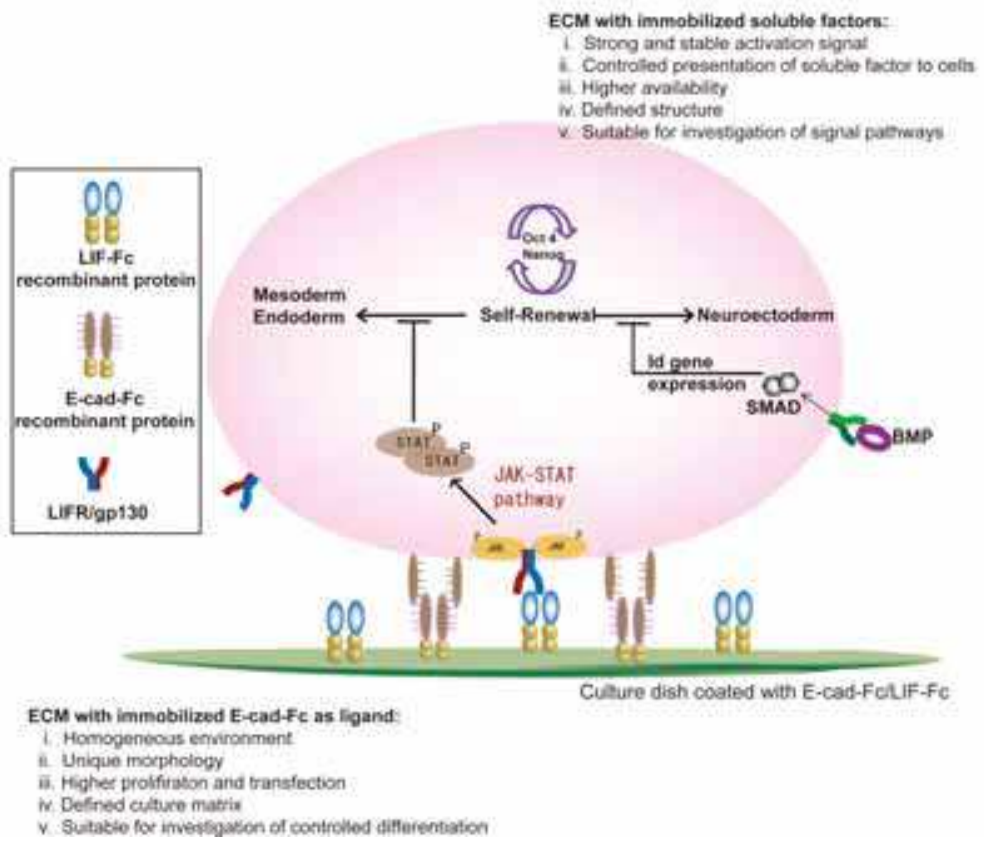

Fig. 3. A proposed model of ES cell pluripotency on artificial extracellular matrix using coimmobilized recombinant fusion protein of E-cadherin and leukemia inhibitory factor (LIF). LIF-dependent activation of STAT3 blocks ES cell differentiation and promotes self-renewal. Oct3/4 and Nanog are the most important transcription factor in this pathway. BMP signal is important to block neurogenesis. Cells on recombinant matrices with single cell morphology with uniform culture conditions and favors homogeneous distribution of signals inside the cell. Specific merits are enumerated in the figure for this culture condition (Friel et al., 2005; Nagaoka et al., 2006; 2008b) 


\subsection{Pluripotency}

Pluripotency is characterized by the ability of a stem cell to self-renew indefinitely while maintaining the capacity to differentiate into derivatives of all three germ layers (ectoderm, endoderm and mesoderm). Pluripotency is the key for ES cells as they can be used for appropriate cell proliferation, cell cycle regulation, gene expression and differentiation. Oct3/4, Nanog and Sox2 are three important transcription factors that can control the maintenance of pluripotency of mouse ES cells by inhibiting differentiation to three germ layers (Nichols et al., 1998; Mitsui et al., 2003; Avilion et al., 2003). Despite clear morphological differences and different growth factor requirements, human ES cells are

(a)

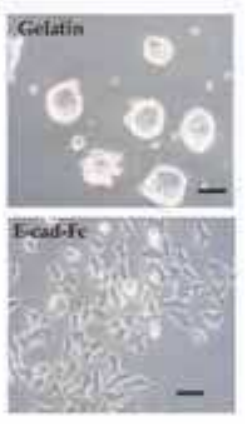

(d)

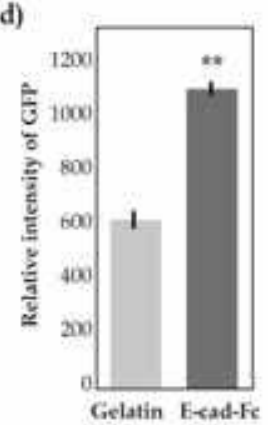

(b)

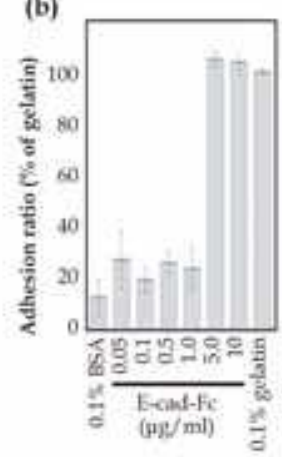

(e)

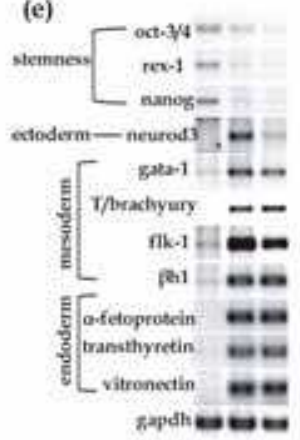

(c)

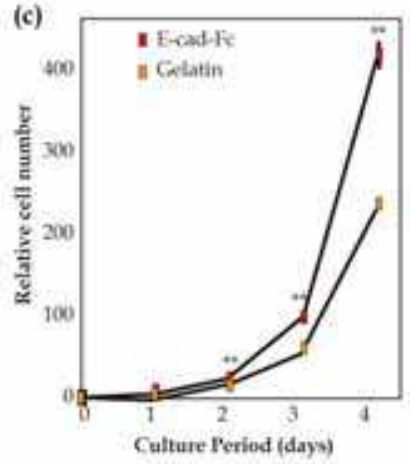

(f)

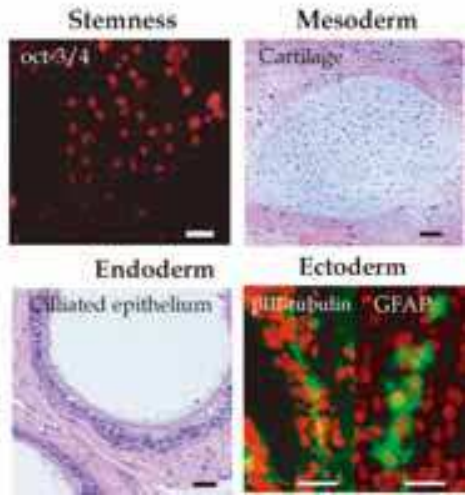

Fig. 4. Advantageous features of ES cells on the E-cad-Fc fusion protein-immobilized surface. (a) Single cell morphology of ES cells (EB3) on E-cad-Fc-coated plate. (b) ES cells adhered to E-cad-Fc-coated dishes with equivalent efficiency as to $0.1 \%$ gelatin-coated dishes after 3 hours of incubation. (c) ES cells show higher proliferation efficiency on the Ecad-Fc-coated surface. (d) Transfection efficiency of ES3 cells cultured on gelatin- or E-cadFc-coated surface. Relative expression of GFP was evaluated. (e, f) Pluripotency of ES cells on E-cad-Fc-coated surface. (e) R1 cells were maintained on gelatin or E-cad-Fc for 26 days, and then were cultured to form embryoid bodies. After 14 days culture of embryoid bodies, expression of marker genes was analyzed by RT-PCR. Lane 1: undifferentiated cells; lane 2: on gelatin; lane 3: on E-cad-Fc. (f) Characterization of teratomas from ES cells (EB3) cultured on an E-cad-Fc-coated surface. The data indicate means \pm SEM. ${ }^{* *}: \mathrm{P}<0.001$ versus gelatinized plates. Scale bar: $50 \mu \mathrm{m}$. Courtesy: Nagaoka et al., 2006 
thought to be equivalent to mouse ES cells at molecular level (Chou et al., 2008). To understand the molecular basis of pluripotency of mouse and human stem cells and to find the common regulatory mechanism, it is necessary to analyze the cells under homogeneous environmental condition at single cell level.

Nagaoka and coworkers (2006, 2008b and 2010b) also showed that both human and mouse ES cells cultured on E-cad-Fc coated surface could be maintained with unique morphological character and complete ES cell features, and that they showed higher proliferative ability and transfection efficiency than those grown under conventional conditions (Fig. 4). Furthermore, they require less LIF, probably due to the homogeneous exposure of cells to LIF that was achieved in this culture system (Nagaoka et al., 2006). Moreover, Cui et al. (2004) reported the heterogeneous distribution of cell-cell adhesion molecules in undifferentiated ES cell colonies. These observations indicate that an aggregated colony formation with close cell-cell communications may generate a heterogeneous environment within the colonies, which potentially inhibit the proliferation of ES cells and the distribution of soluble factors.

A number of new culture methods for ES cells have recently been developed that do not require feeder cells or serum (Xu et al., 2001; Ying et al., 2003b; Sato et al., 2004; James et al., 2005), but a drawback of these methods is that the undifferentiated ES cells form aggregates, which have a potency to inhibit diffusion of soluble factors to cells, and thereby may affect the pluripotency of the cultured cells. Close contact between cells in these aggregates may lead to paracrine interactions with neighboring cells that could generate heterogeneity and initiate differentiation. Furthermore, aggregated cells within the colony cannot be isolated without trypsin treatment which imparts a strong stress on human ES cells and cause massive cell death. It has been reported that culture of human ES cells on E-cad-Fc stabilizes E-cadhein on cell surface by inhibiting endocytosis mediated degradation and thereby, improves ES cell survival after single cell dissociation. Moreover, Xu et al. (2010) also reported that both mouse and human ES cells are much more dependent on E-cadherin than integrin for survival after single cell dissociation in presence of LIF. Therefore, the application of homogeneous single cell culture system using E-cad-Fc and LIF-Fc could be expected to improve the difficulty in culture of ES cells (Fig. 5).

\subsection{Differentiation}

ES cells have enormous potential for the study of embryogenesis at the cell level. However, compared with the generation of pluripotent ES cells, little is known about molecular mechanisms that govern ES cell differentiation. This might be due to lack of homogeneous and defined culture condition to monitor the developmental pathway under single cell level. Until recently, differentiation of ES cells into the three germ layers is attained through the use of specific culture conditions: embryoid-body (EB) formation, cultures on feeder cells, and cultures on matrices. Most cell lineages, including the neuronal, mesoderm and hepatocyte lineages have been shown to be generated within the EB (Nishikawa et al., 2007). However, monitoring cell behavior and guided differentiation to specific cell lineages was not possible without the use of laborious cell sorting (Haque et al., 2010). In contrast, monolayers of freshly isolated cells or cell lines are often used as feeder cells to support EScell activities. The maintenance of human ES cells still requires feeder cells because these cells do not respond to LIF (Thomson et al., 1996). However, the difficulties for using feeder cell lines include maintenance of stromal cell, undefined cultural condition and possibility of pathogen transmission. Considering these limitations, scientists are now focused on the development feeder free culture condition for ES cell culture. 
(a)

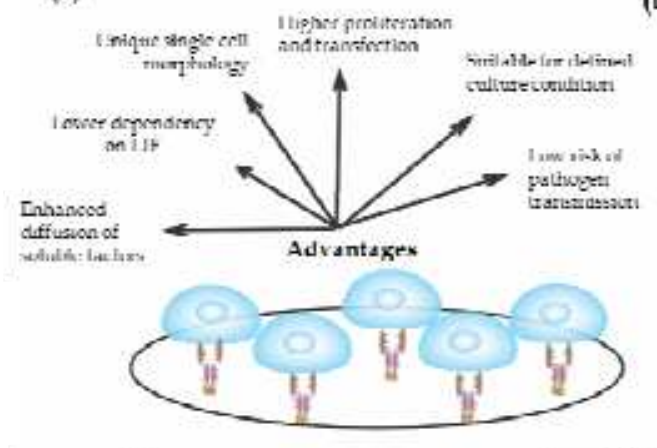

(b)

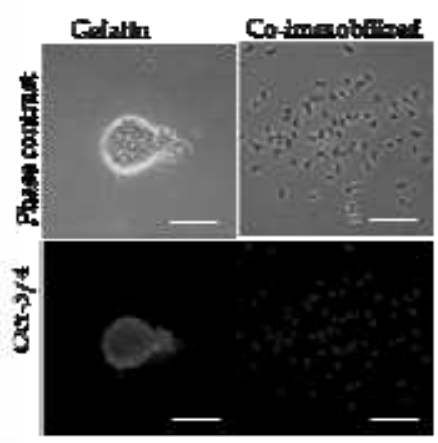

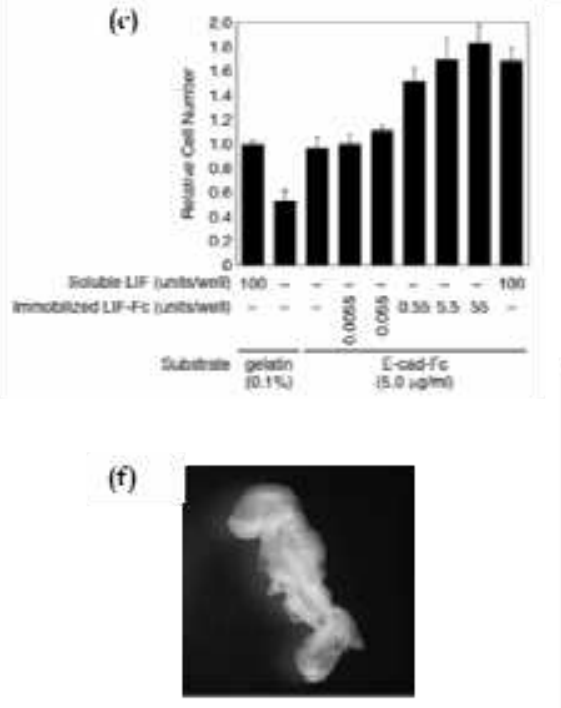

(1)

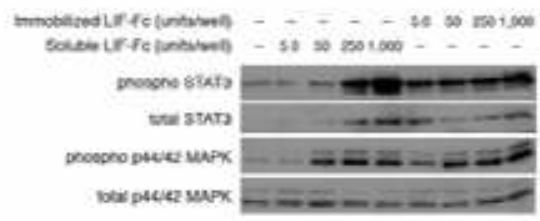

(e)

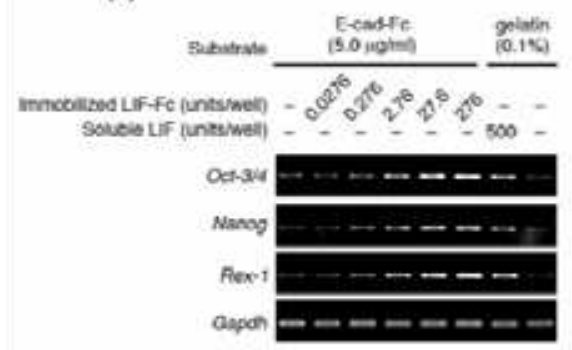

Fig. 5. Cell morphology, adhesion and maintenance of ES cell features on the coimmobilized surface of LIF-Fc and E-cad-Fc. (a) Cells on acellular feeder layer favor single cell culture with homogeneous culture conditions. Specific merits are enumerated in the figure. (b) Morphological observation and expression of pluripotency marker, Oct-3/4 by mouse ES cells (EB3) on a gelatin- or E-cad-Fc-coated surface. (c) The higher proliferative activity of EB3 cells on $5 \mu \mathrm{g} \mathrm{ml}-1$ of E-cad-Fc coated matrix compared to $0.1 \%$ gelatin coated surfaces in the presence of LIF for 2 days. Even at lower concentration of immobilized LIF (LIF-Fc) at 55 units well-1, the ES cells showed higher proliferation ability on a coimmobilized surface than on a gelatinized surface. (d) After culturing for 3 days, the activation of STAT3 and MAPK by immobilized LIF-Fc was analyzed by Western blotting. (e) Expression of three genes that are markers of the undifferentiated state was analyzed by RT-PCR. (f) Feeder-dependent R1 cells were maintained on the co-immobilized surface of Ecad-Fc and LIF-Fc for 10 passages, and then cells were aggregated with four-cell stage tetraploid CD-1 embryos. The embryos were observed at the stage E9.5. Scale bar: $50 \mu \mathrm{m}$. Courtesy: Nagaoka et al., 2008b 
(a)

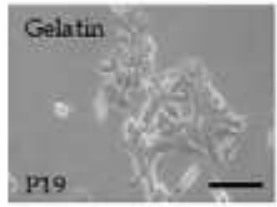

(b)

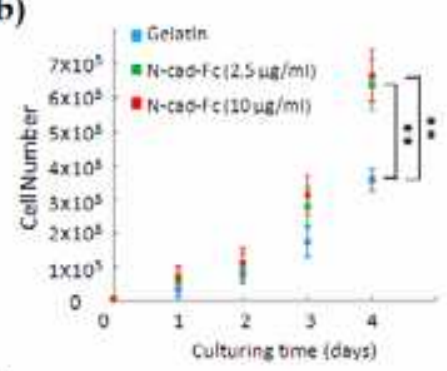

(d)

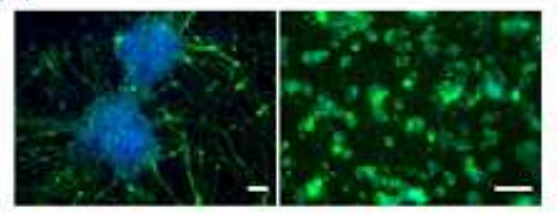

(e)

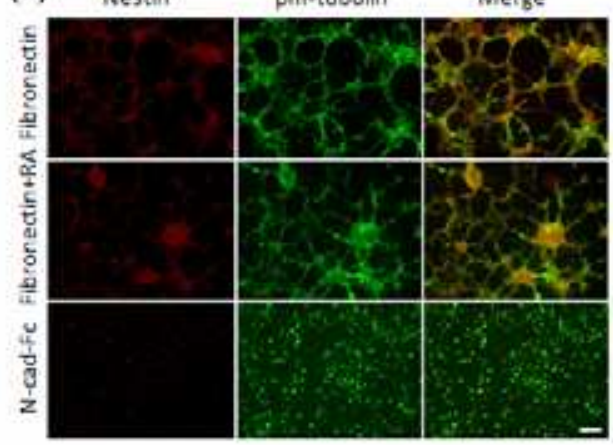

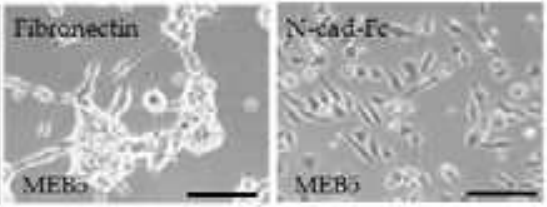

(c)

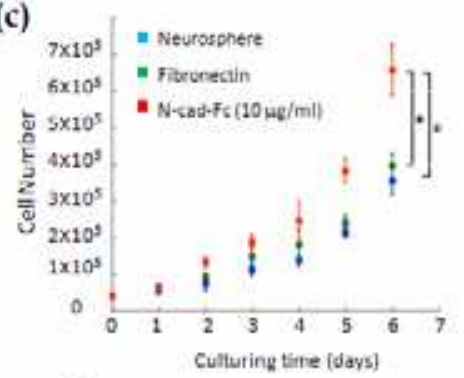

(f)

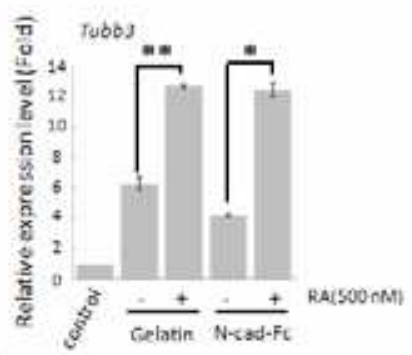

(g)

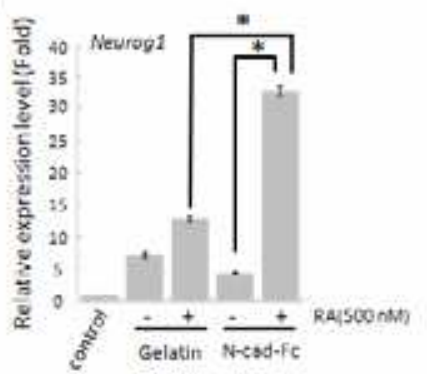

Fig. 6. Morphological observation, cell growth and differentiation P19 embryonal carcinoma and MEB5 neural stem cells. (a) Morphology of P19 and MEB5 cells at day 2 on three different culture matrix. Scale bar: $50 \mu \mathrm{m}$ (left, P19) and $100 \mu \mathrm{m}$ (right, MEB5). The proliferative activity of P19 (b) and MEB5 (c) cells were evaluated. Immunostaining images showing expression of specific neural markers, $\beta$ III-tubulin (green) and Nestin (red) by P19 (d) and MEB5 (e) cells at 6 days of differentiation in presence or absence of retinoic acid (RA). Scale bar: $50 \mu \mathrm{m}$. The quantitative expression level of neural markers, Tubb3 (f) and Neurog1 (g), showing the efficient differentiation potential of P19 cells on N-cad-Fc-coated matrix. The data indicates means \pm SD $(n=3) .{ }^{*} p<0.01,{ }^{* *} p<0.001$. Courtesy: Yue et al., 2010 
For ES-cell differentiation in monolayer cultures under chemically defined conditions, only a few successes have been reported. Ying and coworkers showed that differentiation of ES cells to neuronal cells can be induced on gelatin-coated dishes with a conventional serum-free medium. Researchers also reported two serum-free conditions for definitive endoderm and visceral endoderm that are based on the serum-free medium in the presence of insulin, transferring and bovine serum albumin (Yasunaga et al., 2005). Under these conditions, the purity of the cells was achieved after laborious cell sorting using flow cytometry, which is practically impossible to billions of differentiated cells for therapeutic applications. Therefore, single cell culture on artificial ECM using the chimeric proteins of E-cadherin or growth factors could be the ultimate target to obtain homogeneous population of non-stressed differentiated cells at high efficiencies. Yue et al. (2010) showed that differentiation of ES cells to neuronal cells can be achieved on N-cadherin dependent artificial ECM (N-cad-Fc). Both P19 embryonal carcinoma cells and MEB5 neural stem cells cultured on N-cad-Fc-coated surface showed scattering morphologies without colony formation and higher proliferating potency than conventional culture systems with maintenance of undifferentiated state (Fig. 6). Both of two cell lines cultured on N-cad-Fc-coated surface differentiated into neural cells under single cell level. Furthermore, the expression of neuron-related markers, Tubb3, Nestin and Neurog1, in two cell lines cultured on N-cad-Fc-coated surface was much higher than colony forming conditions on gelatin-coated plates. Therefore, it will be expected that the constructed $\mathrm{N}$-cad-Fc can be used as an artificall ECM for neural differentiation of stem cells to overcome the existing problems of convensional culture systems.

\section{Conclusion and future perspectives}

Biomaterials have already had an enormous impact on health care, and are already widely used in biomedical applications. However, relatively less effort has been made to use synthetic nanobiomaterials in embryonic stem cell research. Until recently, cell and matrix biologists have almost exclusively used natural ECM-derived materials as 3-D model systems. Precise control over extracellular microenvironment using engineered ECM would be useful to fulfill the huge demand of cells for transplantation in tissue engineering and regenerative medicine for development of bioartificial organs. Also, there will be increasing demands that 3-D recombinant fusion proteins provide better model systems for physiologic situations because 3-D fusion proteins induce more effctively cellular functions than 2-D ones although 2-D in vitro assay on 2-D recombinant fusion proteins are still applied in many cell culture studies. Moreover, the construction of lineage specific ECM to enrich specific population of cells for transplantation has not yet been developed. Matrix dependent selective induction of ES cells to uniform population of cells can significantly enrich specific population of differentiated cells for biomedical applications without the need for any laborious cell sorting and purification to eliminate contaminating cells. Furthermore, future research will be aimed to the design of hybrid materials consisting of intelligent recombinant proteins and other biomaterials with high mechanical characteristics for understanding developmental pathways of human ES or iPS cell-derived differentiated cells.

\section{References}

Akhyari, P.; Kamiya, H.; Haverich, A.; Karck, M. \& Lichtenberg, A. (2008). Myocardial tissue engineering: the extracellular matrix. European eburnal of Cardio-thoracic Surgery, 34, 2, (229-241). 
Avilion, AA.; Nicolis, SK.; Pevny, LH.; Perez, L.; Vivian, N. \& Lovell-Badge, R. (2003). Multipotent cell lineages in early mouse development depend on SOX2 function. Genes and Development, 17, 1, (126-140).

Azuma, K.; Nagaoka, M.; Cho, CS. \& Toshihiro Akaike. (2010). An artificial extracellular matrix created by hepatocyte growth factor fused to IgG-Fc. Biomaterials, 31, 5, (802-809).

Brieher, WM.; Yap, AS. \& Gumbiner, BM. (1996). Lateral dimerization is required for the homophilic binding activity of C-cadherin. eburnal of Cell Biology, 135, 2, (487-496).

Cho, CS.; Seo, SJ.; Park, IK.; Kim, SH.; Kim, TH.; Hoshiba, T.; Harada, I. \& Akaike, T. (2006). Galactose-carrying polymers as extracellular matrices for liver tissue engineering. Biomaterials, 27, 4, (576-585).

Chou, YF.; Chen, HH.; Eijpe, M.; Yabuuchi, A.; Chenoweth, JG.; Tesar, P.; Lu, J.; McKay, RDG. \& Geijsen, N. (2008). The growth factor environment defines distinct pluripotent ground states in novel blastocyst-derived stem cells. Cell, 135, 3, (449461).

Cui, L.; Johkura, K.; Yue, F.; Ogiwara, N.; Okouchi, Y.; Asanuma, K. \& Sasaki, K. (2004). Spatial distribution and initial changes of SSEA-1 and other cell adhesion-related molecules on mouse embryonic stem cells before and during differentiation. The eburnal of Histochemistry and Cytochemistry, 52, 11, (1447-1457).

Discher, DE.; Mooney DJ. \& Zandstra PW. (2009). Growth factors, matrices, and forces combine and control stem cells. Science, 324, 5935, (1673-1677).

Eschenhagen, T.; Fink, C.; Remmers, U.; Scholz, H.; Wattchow, J.; Weil, J.; Zimmermann, W.; Dohmen, HH.; Schafer, H.; Bishopric, N.; Wakatsuki, T. \& Elson, EL. (1997). Threedimensional reconstitution of embryonic cardiomyocytes in a collagen matrix: a new heart muscle model system. FASEB eburnal, 11, 8, 683-694.

Friel, R.; Sar, S. \& Mee, PJ. (2005). Embryonic stem cells: Understanding their history, cell biology and signalling. Advanced Drug Delivery Reviews, 57, 13, (1894-1903).

Gupta, B.; Plummer, C.; Bisson, I.; Frey, P. \& Hilborn, J. (2002). Plasma induced graft polymerization of acrylic acid onto poly(ethyleneterephthalate) films: characterization and human smooth muscle cell growth on grafted films. Biomaterials, 23, 3, (863-871).

Haque, MA.; Nagaoka, M.; Hexig, B. \& Akaike, T. (2010). Artificial extracellular matrix for embryonic stem cell cultures: a new frontier of nanobiomaterials. Science and Technology of Advanced Materials, 11, 014106 (1-9).

Hynes RO. (1999). Cell adhesion: old and new questions. Trends in Cell Biology, 9, 12, (M3337).

James, D.; Levine, AJ.; Besser, D. \& Hemmati-Brivanlou, A. (2005). TGF $\beta$ /activin/ nodal signaling is necessary for the maintenance of pluripotency in human embryonic stem cells. Development, 132, 6, (1273-1282).

Langer, R. \& Tirrell, DA. Designing materials for biology and medicine. (2004). Designing materials for biology and medicine. Nature, 428, 6982 (487-492).

Larue, L.; Ohsugi, M.; Hirchenhain, J. \& Kemler, R. (1994). E-cadherin null mutant embryos fail to form a trophectoderm epithelium. Proceedings of the National Academy of Sciences of the USA, 91, 17, (8263-8267). 
Lutolf, MP. \& Hubbell. JA. (2005). Synthetic biomaterials as instructive extracellular microenvironment for morphogenesis in tissue engineering. Nature Biotechnology, 23, 1, (47-55).

Mitsui, K.; Tokuzawa, Y.; Itoh, H.; Segawa, K.; Murakami, M.; Takahashi, K.; Maruyama, M.; Mayeda, M. \& Tamanaka, S. Cell. 113, 5, (631-642).

Miyatani, S.; Shimamura, K.; Hatra, M; Nagafuchi, A.; Nose, A.; Matsunaga, M.; Hatra, K. \& Takeichi, M. (1989). Neural cadherin: role in selective cell-cell adhesion. Science, 245, 4918, (631-635).

Nagaoka, M.; Ise, H. \& Akaike T. (2002). Immobilized E-cadherin model can enhance cell attachment and differentiation of primary hepatocytes but not proliferation. Biotechnology Letters, 24, (1857-1862).

Nagaoka, M.; Koshimizu, U.; Yuasa, S.; Hattori, F.; Chen, H.; Tanaka, T.; Okabe, M.; Fukuda, K. \& Akaike, T. (2006). E-cadherin-coated plates maintain pluripotent ES cells without colony formation. PLoS One, 1, e15.

Nagaoka, M.; Ise, H.; Harada, I.; Koshimizu, U.; Maruyama, A. \& Akaike, T. (2008a). Embryonic undifferentiated cells show scattering activity on a surface coated with immobilized E-cadherin. eburnal of Cellular Biochemistry, 103, 1, (296-310).

Nagaoka, M.; Hagiwara, Y.; Takemura, K.; Murakami, Y.; Li, J.; Duncan, SA. \& Akaike, T. (2008b). Design of the artificial acellular feeder layer for the efficient propagation of mouse embryonic stem cells JBiol Chem, 283, 39, (26468-26476)..

Nagaoka, M.; Jiang, HL.; Hoshiba, T.; Akaike, T. \& Cho CS. (2010a). Application of recombinant fusion proteins for tissue engineering. Annals of Biomedical Engineering, 38, 3, (683-693).

Nagaoka, M.; Si-Tayeb, K.; Akaike, T. \& Duncan, SA. (2010b). Methodology article Culture of human pluripotent stem cells using completely defined conditions on a recombinant E-cadherin substratum. BMC Developmental Biology, 10, 60, (1-12).

Nichols, J.; Zevnik, B.; Anastassiadis, K.; Niwa, H.; Klewe-Nebenius, D.; Chambers, I.; Scholer, H. \& Smith, A. Formation of pluripotent stem cells in the mammalian embryo depends of the POU transcription factor Oct4. Cell, 95, 3, (379-391).

Nishikawa, SI.; Jakt, LM. \& Era, T. (2007). Embryonic stem-cell culture as a tool for developmental cell biology. Nature Reviews: Molecular Cell Biology, 8, 6, (502-507).

Ogiwara, K.; Nagaoka, M.; Cho, CS. \& Akaike, T. (2005). Construction of a novel extracellular matrix using a new genetically engineered epidermal growth factor fused to IgG-Fc. Biotechnology Letters, 27, (1633-1637).

Ozawa, M.; Ringwald, M. \& Kemler, R. (1990). Uvomorulin-catenin complex formation is regulated by a specific domain in the cytoplasmic region of the cell adhesion molecule. Proceedings of the National Academy of Sciences of the USA, 87, 11, (42464250).

Parashurama, N.; Nahmias, Y.; Cho, CH.; Poll, DV.; Tilles, AW.; Berthiaume, FO. \& Yarmush, ML. Activin alters the kinetics of endoderm induction in embryonic stem cells cultured on collagen gels. Stem Cells, 26, 2, (474-484).

Putnam, AJ. \& Mooney, DJ. (1996). Tissue engineering using synthetic extracellular matrices. Nature Medicine, 2, 7, (824-6).

Riethmacher, D.; Brinkmann, V. \& Birchmeier, C. (1995). A targeted mutation in the mouse E-cadherin gene results in defective preimplantation development. Proceedings of the National Academy of Sciences of the USA, 92, 3, (855-859). 
Sato, N.; Meijer, L.; Skaltsounis, L.; Greengard, P. \& Brivanlou, AH. (2004). Maintenance of pluripotency in human and mouse embryonic stem cells through activation of Wnt signaling by a pharmacological GSK-3-specific inhibitor. Nature Medicine, 10, 1, (5563).

Takeichi, M.; Atsumi, T.; Yoshida, C.; Uno, K. \& Okada, TS. (1981). Selective adhesion of embryonal carcinoma cells and differentiated cells by $\mathrm{Ca}^{2+}$-dependent sites. Developmental Biology, 87, 2, (340-350).

Takeichi, M. Morphogenetic roles of classic cadherins. (1995). Current Opinion in Cell Biology, 7, 5, (619-627).

Tanaka, Y.; Kimata, K.; Adams, DH. \& Eto, S. (1998). Modulation of cytokine function by heparan sulfate proteoglycans: sophisticated models for the regulation of cellular responses to cytokines. Proceedings of the Association of American Physicians, 110, 2, (118-125).

Thomson, JA.; Kalishman, J.; Golos, TG.; Durning, M.; Harris, CP. \& Hearn, JP. (1996). Pluripotent cell lines derived from common marmoset (Callithrix jacchus) blastocysts. Biology of Reproduction, 55, 2, (254-259).

Williams, EJ.; Williams, G.; Howell, FV.; Skaper, SD.; Walsh, FS. \& Doherty, P. (2001). Identification of an $\mathrm{N}$-cadherin motif that can interact with the fi broblast growth factor receptor and is required for axonal growth. eburnal of Biological Chemistry, 276, 47, 43879-86.

Xu, C.; Inokuma, MS.; Denham, J.; Golds, K.; Kundu, P.; Gold, JD. \& Carpenter, MK. (2001). Feeder-free growth of undifferentiated human embryonic stem cells. Nature Biotechnology, 19, 10, (971-974).

Xu, Y.; Zhu, X.; Hahm, SK.; Wei, W.; Hao, E.; Hayek, A. \& Ding, S. (2010). Revealing a core signaling regulatory mechanism for pluripotent stem cell survival and self-renewal by small molecules. Proceedings of the National Academy of Sciences of the USA, 107, 18, (8129-8134).

Yasunaga, M.; Tada, S.; Nishikawa, ST.; Nakano, Y.; Okada, M.; Jakt, LM.; Nishikawa, S.; Chiba, T.; Era, T. \& Nishikawa, SI. (2005). Induction and monitoring of definitive and visceral endoderm differentiation of mouse ES cells. Nature Biotechnology, 23, 12, (1542-1550).

Ying, QL.; Nichols, J.; Chambers, I. \& Smith, A. (2003a). BMP induction of Id proteins suppresses differentiation and sustains embryonic stem cell self-renewal in collaboration with STAT3. Cell, 115, (281-292).

Ying, QL.; Stavridis, M.; Griffiths, D.; Li, M. \& Smith, A. (2003b). Conversion of embryonic stem cells into neuroectodermal precursors in adherent monoculture. Nature Biotechnology, 21, 2, (183-186).

Yue, XS.; Murakami, Y.; Tamai, T.; Nagaoka, M.; Cho CS..; Ito, Y. \& Akaike T. (2010). A fusion protein $\mathrm{N}$-cadherin-Fc as an artificial extracellular matrix surface for maintenance of stem cell features. Biomaterials, 31, 20, (5287-5296). 


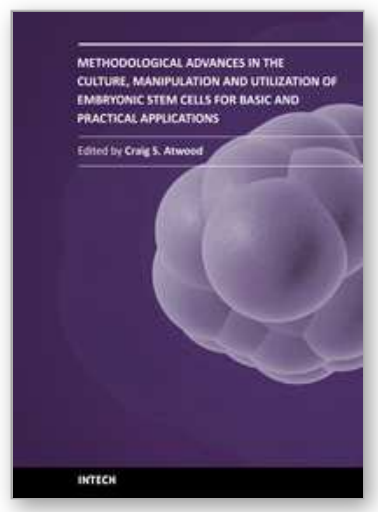

\author{
Methodological Advances in the Culture, Manipulation and \\ Utilization of Embryonic Stem Cells for Basic and Practical \\ Applications \\ Edited by Prof. Craig Atwood
}

ISBN 978-953-307-197-8

Hard cover, 506 pages

Publisher InTech

Published online 26, April, 2011

Published in print edition April, 2011

Pluripotent stem cells have the potential to revolutionise medicine, providing treatment options for a wide range of diseases and conditions that currently lack therapies or cures. This book describes methodological advances in the culture and manipulation of embryonic stem cells that will serve to bring this promise to practice.

\title{
How to reference
}

In order to correctly reference this scholarly work, feel free to copy and paste the following:

Amranul Haque, Masato Nagaoka, Xiao-Shan Yue, Stephen A. Duncan and Toshihiro Akaike (2011). Artificial Acellular Feeder Layer: An Advanced Engineered Extracellular Matrix for Stem Cell Culture, Methodological Advances in the Culture, Manipulation and Utilization of Embryonic Stem Cells for Basic and Practical Applications, Prof. Craig Atwood (Ed.), ISBN: 978-953-307-197-8, InTech, Available from:

http://www.intechopen.com/books/methodological-advances-in-the-culture-manipulation-and-utilization-ofembryonic-stem-cells-for-basic-and-practical-applications/artificial-acellular-feeder-layer-an-advancedengineered-extracellular-matrix-for-stem-cell-culture

\section{INTECH}

open science | open minds

\section{InTech Europe}

University Campus STeP Ri

Slavka Krautzeka 83/A

51000 Rijeka, Croatia

Phone: +385 (51) 770447

Fax: +385 (51) 686166

www.intechopen.com

\section{InTech China}

Unit 405, Office Block, Hotel Equatorial Shanghai No.65, Yan An Road (West), Shanghai, 200040, China 中国上海市延安西路65号上海国际贵都大饭店办公楼 405 单元 Phone: +86-21-62489820

Fax: +86-21-62489821 
(C) 2011 The Author(s). Licensee IntechOpen. This chapter is distributed under the terms of the Creative Commons Attribution-NonCommercialShareAlike-3.0 License, which permits use, distribution and reproduction for non-commercial purposes, provided the original is properly cited and derivative works building on this content are distributed under the same license. 